\title{
Introverted goalie versus extraverted center? Comprehensive investigation of Big Five personality traits within and between team sports
}

\author{
Sophia Terwiel ${ }^{\mathrm{a} *} \&$ Sarah Kritzler ${ }^{\mathrm{a} *}$
}

aDepartment of Psychology, Ruhr University Bochum

This is a preprint version of a manuscript submitted for publication. It might be published in a different version in the future.

Version: March 2021

The study design was preregistered on OSF:

https://osf.io/98hu3/?view_only=144ccb99750447959bf8ba00a62340ef.

Data, analysis scripts, and online supplementary materials (OSM) are openly available online: https://osf.io/aew3g/?view_only=7f7d3220febf4094a00d649736842c3a.

\section{Author Note}

Sophia Terwiel (D) https://orcid.org/0000-0002-0278-4609

Sarah Kritzler (D) https://orcid.org/0000-0002-9682-1502

Correspondence concerning this article should be addressed to Sophia Terwiel, Email: sophial.terwiel@rub.de.

*equal contributions 


\begin{abstract}
Objectives

In team sports, many anecdotes and stereotypes report personality differences between athletes of different playing positions. However, by now research shows ambiguous results and often only single sports have been examined. This preregistered study, thus, represents a first comprehensive investigation of differences in personality traits of athletes (1) performing different team sports, (2) being offense players and defense players, as well as (3) playing on different positions.
\end{abstract}

\title{
Design
}

In an online survey, we assessed self-reported Big Five personality traits for 2,322 athletes of 16 different (popular - e.g. Basketball and less-known - e.g. Quidditch) team sports using the BFI-2-S (Soto \& John, 2017). Further, we assessed their role in the offense and defense phases of a game, their specific playing position as well as demographic and sportrelated information.

\section{Method}

We descriptively and statistically investigated differences between personality profiles of different team sports, between offense and defense players within sports, and between playing positions within sports. Additionally, we compared different approaches to assessing offense and defense positions.

\section{Results}

Athletes playing different team sports significantly differed in the personality traits Extraversion, Conscientiousness, and Openness. However, these effects were small ( $\eta^{2}$ ranging from .01 to .02). Similarly, offense players were found to be significantly more extraverted than defense players, but the effect was again small $\left(\eta_{\mathrm{p}}{ }^{2}=.003\right)$. Athletes playing offense and defense positions did not significantly differ in any other personality traits regardless of how we operationalized offense and defense. However, we demonstrated that not all playing 
positions may be easily categorized into offense and defense. Finally, athletes of different playing positions did not differ significantly in their personality traits. As the only exception, Floorball centers were significantly more extraverted than Floorball defenders explaining only about $5 \%$ of the variance in trait extraversion scores.

\section{Conclusion}

Our comprehensive investigation demonstrates that there is only a little evidence for differences in Big Five traits for athletes of different team sports and between athletes being offense or defense players, or athletes playing on different playing positions. Thus, ascribed personality differences might indeed just be reflecting stereotypes.

\section{Keywords}

Playing position, personality traits, team sports, Big Five 


\section{Introverted goalie versus extraverted center? - Comprehensive investigation of Big Five traits within and between team sports}

Typically, in team sports, there are different playing positions like goalkeepers, centers, or quarterbacks. Identifying the best player for a given playing position in team sports has always been a challenging task for coaches and scouts. What characteristics make Manuel Neuer, Marc-André ter Stegen, or Jan Oblak one of the best soccer goalkeepers of the current times? Could they also have been outstanding forwards or are they particularly well-suited for their specific position?

Playing positions differ regarding the tasks that need to be done, their typical locations on the pitch or field or their running lines, and sometimes even regarding the rules that apply to players (e.g., goalkeeper). Such differences between the various playing positions suggest that the players playing those positions should also differ from each other. It has indeed been found that players in different positions differ in their body composition (e.g. Fields et al., 2018), skills, and abilities (Karcher \& Buchheit, 2014; Rogulj et al., 2005). Besides, players of different positions might differ is in their psychological dispositions, such as their personality. For example, an athlete on a position whose job it is to coordinate and lead the team-such as a central midfielder - may typically be more extraverted than athletes on a position that is predominantly self-reliant and independent of others — such as a goalkeeper.

However, differences in personality traits of players playing different positions have been investigated rather unsystematically, mostly focusing only on single sports (e.g., handball or soccer) and using different measures, conceptualizations, and research designs. This leads to a lack of generalizability of findings across sports and positions. Besides, current findings are rather mixed. Whereas some studies reported only differences between offense and defense players for some team sports (Beckmann \& Trux, 1991; Kirkcaldy, 1982a; Schurr et al., 1984), other studies reported even differences between single positions (Čavala et al., 2013; Kőnig- 
Görögh et al., 2017; Kruse, 1977; Rogulj et al., 2005; Sindik, 2011), and still others reported no differences at all (Cameron et al., 2012).

Therefore, the present study represents a first comprehensive investigation of differences in Big Five personality traits of athletes (1) performing different team sports, (2) being offense and defense players, as well as (3) playing in different positions. We address important gaps in the literature by including and comparing a wide selection of different team sports and position types in one study and thereby providing comparable and generalizable findings regarding personality differences in team sport athletes.

\section{The Role of Personality in Sports}

Personality traits are the relatively stable characteristics of a person expressed in their typical ways of thinking, feeling, and behaving (Diener \& Lucas, 2020). Sports and physical activity have been related to personality across the life-span (Allen et al., 2017; Bakker, 1991; Rhodes \& Smith, 2006; Wilson \& Dishman, 2015) and have been linked to several outcomes like performance (Allen \& Laborde, 2014) and well-being (Downward \& Rasciute, 2011). Hereby, identifying differences in personality traits between different groups of people has a long history in sport psychological research (Garland \& Barry, 1988; Kirkcaldy, 1982a, 1982b; Morgan \& Pollock, 1977; Nation \& LeUnes, 1983; Ogilvie \& Pool, 1974; Schurr et al., 1984). Differences in personality traits have been found for athletes versus non-athletes (Rhodes \& Smith, 2006; Zekioglu et al., 2018), athletes of different sports (Aidman \& Schofield, 2004; Castanier et al., 2010; Nia \& Besharat, 2010; Rhea \& Martin, 2010), and athletes of different achievement levels (Kirkcaldy, 1982b; Schurr et al., 1984; Sheard \& Golby, 2010).

A widely accepted model comprising the major factors of personality are the Big Five personality traits (Costa \& McCrae, 1992; McCrae \& Costa, 1987) Openness to Experience, Conscientiousness, Extraversion, Agreeableness, and Neuroticism (for example items see Table 1). Importantly, these traits describe personality dimensions, that is, people are not placed in categories such as introvert or extravert but are characterized by their level of extraversion on 
a continuum from introversion to extraversion. The Big Five have been used to identify differences between groups of people in several different contexts, like the work environment (Denissen et al., 2018), different cultures (Schmitt et al., 2007), pet preference (Gosling, Sandy, \& Potter, 2010), or even the Hogwarts houses from Harry Potter (Crysel et al., 2015; Jakob et al., 2019). Returning to the role of personality in sport, the Big Five have been related to athletic behavior (Allen et al., 2011) and performance (Allen \& Laborde, 2014). Further, high-risk athletes were found to be more extraverted and less conscientious than other athletes (Castanier et al., 2010; Evans et al., 2012; Rhea \& Martin, 2010) and more extraverted, open to experience, and less conscientious than non-athletes (Tok, 2011). Endurance sport athletes are more extraverted compared to non-athletes (Egloff \& Jan Gruhn, 1996). Additionally, personality traits differentiate between team sport athletes and combat sport athletes (Bojanić et al., 2019). Team sport athletes are less conscientious and more extraverted than individual sport athletes (Allen et al., 2011; Eagleton et al., 2007; Nia \& Besharat, 2010). Even though most studies did not find personality differences between single sports (Johnson \& Morgan, 1981; O'Sullivan et al., 1998), Trninić et al. (2016) found differences in conscientiousness and openness to experience between water polo, handball, and football players. Thus, overall, there is currently only little research on and evidence for differences in personality traits of athletes of different team sports.

\section{Playing Position}

In team sports, the selection of players for specific positions has always been one of the main tasks for coaches and staff. Playing in a specific position in a sport often implies having specific tasks (e.g., catching the ball), being responsible for a specific area (e.g., left center), or being allowed to do specific things (e.g., catching the ball with hands). Thus, different playing positions pose different demands on the athletes playing them, for example in terms of relevant skills (Karcher \& Buchheit, 2014; Rogulj et al., 2005), physical demands (e.g. Fields et al., 
2018), and also individual psychological characteristics (Beckmann \& Trux, 1991; e.g. Cox \& Yoo, 1995; Rogulj et al., 2005).

One relevant example of such psychological characteristics are personality traits. Personality traits have been assumed to differ for players on different playing positions (for a review see Allen \& Laborde, 2014). For basketball players, it has been found that those on playmaker positions were more state-oriented than those playing on rather action-oriented center positions (Beckmann \& Trux, 1991). In soccer, attacking players were found to be more self-oriented than defense players (Cooper \& Payne, 1972), and Kruse (1977) even found distinct trait profiles for goalkeepers, midfield players, and defense players. In handball, pivots showed higher degrees of psychotic behavior (Rogulj et al., 2005). However, these studies all focused on specific sports and examined different and rather narrow personality constructs.

In a broader approach to personality, several studies also examined differences in position specificity for Big Five personality traits. However, as the following examples demonstrate, the findings have been quite mixed and are difficult to integrate across different sports, positions, and personality traits. In one of the first studies concerning position-specific personality in sports, it has been found that athletes playing in offense positions were less emotionally-stable, but more extraverted than players playing in defense positions (Kirkcaldy, 1982a). Since then, the Big Five traits have been investigated for several different sports and positions. For basketball players, it has been found that players of different positions can be distinguished based on particular dimensions of the Big Five traits (Sindik, 2011). In handball, goalkeepers were lower in extraversion than outside players, wings, and pivots (Čavala et al., 2013), as well as higher in conscientiousness and neuroticism and lower in openness to experience than the normal population but not than players on other positions (Fasold et al., 2020). Moreover, backcourt players and goalkeepers were less agreeable than other players (Kőnig-Görögh et al., 2017), and wings were higher in extraversion (Rogulj et al., 2005). In 
contrast, Cameron et al. (2012) found no differences in the self-reported Big Five traits for hockey players playing in the offense, the defense, or the goalkeeper position.

In summary, the current evidence for differences in personality traits for athletes of different playing positions in general but especially for the Big Five is mixed-some studies found significant differences between players of different positions, some only for specific comparisons, and some found no differences at all. Additionally, the current findings are not generalizable because studies often focused on single sports, and personality measures, research designs, and conceptualizations of personality differed across studies. Moreover, whereas some studies differentiated between the specific positions within a sport, others reverted to a broader distinction between offense and defense players. Thus, a more systematic and comprehensive investigation of personality differences in playing positions of different sports is needed.

\section{The Present Study}

In the current study, we examined personality profiles in athletes playing team sports. In a first step, we investigated differences between athletes of different team sports. In a second step, we investigated differences between offense and defense players of different team sports, which represents the most commonly used distinction of playing positions concerning personality differences (Cameron et al., 2012; Cooper \& Payne, 1972; Cox \& Yoo, 1995; Kirkcaldy, 1982a). In a third step, we also investigated sport-specific positions (e.g., goalkeeper) for single sports. Due to the mixed evidence regarding the difference in personality traits for players of different team sports or playing positions, we did not formulate concrete hypotheses. Instead, the present study comprehensively investigated the Big Five personality traits for athletes of different team sports concerning the following research questions:

1. Are there differences in Big Five personality traits between athletes of different team sports?

2. Are there differences in Big Five personality traits between athletes playing on offense and defense positions? 
3. Are there differences in Big Five personality traits between athletes playing different playing positions within sports?

\section{Methods}

Data collection was approved by the local ethics committee of [INSTITUTION BLINDED FOR PEER REVIEW]. The preregistration of the study design can be found at https://osf.io/98hu3/?view_only=144ccb99750447959bf8ba00a62340ef. Data, analysis scripts, and online supplementary materials (OSM) are available online (https://osf.io/aew3g/?view_only=7f7d3220febf4094a00d649736842c3a).

\section{Procedure and Sample}

A large-scale online survey in English was provided with the survey tool Qualtrics (Qualtrics, 2020) ${ }^{1}$. Participants were recruited via general and sport-specific channels and groups of social media platforms like reddit, Facebook, and forums, and via preexisting mailing lists of interested participants. After providing informed consent and confirming that they were at least 18 years old and regularly practiced one of the listed team sports in the last year, participants answered 20 minutes of questions regarding their individual personality as well as sport-specific questions (e.g., training hours per week) and position-specific questions (e.g., main playing position). ${ }^{2}$ To compensate for their participation, participants received feedback on their individual personality profiles at the end of the survey.

As there are no existing data on systematic investigations of personality traits for different playing positions of athletes of several different sports to our knowledge, we could not calculate the required sample size based on previously reported effect sizes. Instead, we recruited as many participants as possible. Due to the different popularity of the sports and the

\footnotetext{
${ }^{1}$ Data collection took place from April 2020 to February 2021 during the Covid-19 pandemic changing normal life and also exercise behavior or almost everyone. However, we assume that the variables of interest (personality and sport or player position) were not significantly affected (see Discussion).

2 The presented data are part of a survey that further assessed different characteristics (e.g., situational perception) for athletes playing in different positions in team sports. For further information see the preregistration of the study design and the survey flow: https://osf.io/98hu3?view_only=144ccb99750447959bf8ba00a62340ef
} 
different frequencies of the positions, we expected differences in the sample for the frequencies of different sports and playing positions.

A total of 2,624 athletes participated in the study. Participants were excluded if they indicated careless responding on the data quality items $(N=84)$. Moreover, we excluded sports with less than 30 participants which lead to the exclusion of 141 additional participants. The final sample thus consisted of 2,322 participants (77\% male, $22 \%$ female, and $1 \%$ diverse) with a mean age of 27.16 years $(S D=7.75)$. We employed pairwise deletion to deal with missing data. That is, participants were excluded from single analyses if they did not provide data on relevant constructs, but they could still be included in other analyses. Table 2 presents the number of participants, age, and gender distributions separately for each sport.

\section{Measures}

\section{Sport}

Participants indicated which team sport they performed most often based on a list of 24 team sports. Only sports that were rated by more than 30 participants were included in the final sample ( $N=16$ team sports). A complete list of sports included in the survey with the number of participants can be found in the OSM.

\section{Position}

Playing Position To indicate their main playing position, participants were asked to choose from a list of all positions given in their sport (see OSM). Only positions which were rated by at least 5 participants were included in analyses focusing on playing positions $(N=88$ positions from 16 different sports) $)^{3}$. Further, participants could give additional information

\footnotetext{
${ }^{3}$ The playing positions for the different sports were compiled based on Internet research on playing positions, personal experience of researchers involved in the project, and information given by expert raters in a qualitative pilot study. In the online pilot-study $\mathrm{N}=30$ athletes of $\mathrm{k}=21$ team sports were asked open questions regarding playing positions of their sports and offense and defense phases of the game.
} 
about their playing position in a comment field. Information given in the comment field was used to exclude sports or positions. ${ }^{4}$

Offense and defense The distinction between offense and defense positions was assessed in two ways for each participant. First, participants had to indicate whether their main playing position was mainly offense or a defense in a forced-choice question (offense-defense categorization). Second, participants indicated how much their main playing position is typically involved in offense and defense phases of the game, rating both dimensions independently on a scale from 0 to $100 \%$ (offense and defense involvement). ${ }^{5}$

\section{Big Five}

Participants' Big Five personality traits were assessed using the BFI-2-S which comprises a total of 30 items, that is, six items per trait (Soto \& John, 2017). Participants indicated how much they agreed with different trait-descriptive statements on a Likert-scale ranging from 1 (disagree strongly) to 5 (agree strongly). Sample items, means, standard deviations, and internal consistencies for each trait are listed in Table 1.

\section{Analyses}

All statistical analyses were performed using R Version 4.0.3 (R Core Team, 2020). We used descriptive statistics and graphics to describe differences and similarities in personality profiles between athletes from different team sports, between athletes playing offense or defense positions, and between athletes playing different main position within sports. Moreover, we used variance analyses and multilevel regression analyses to examine whether there were statistically significant differences for those comparisons. Because all analyses were

\footnotetext{
${ }^{4}$ We excluded Baseball players from all statistical analyses examining differences between offense and defense and Baseball, Volleyball, and Water Polo players from all analyses examining differences between playing positions as athletes reported that either positions were switched between offense and defense phases or rotated during the game. We still examined those sports graphically and descriptively.

${ }^{5}$ The decision to access offense and defense positions in different ways was informed by a qualitative pilot-study, in which the participants for several sports indicated that the distinction between offense and defense positions was not given in all cases.
} 
run separately for each of the Big Five personality traits, we used a Bonferroni-corrected significance level of $\alpha=.01$ for all analyses.

\section{Results}

Data, analysis scripts, and comprehensive online supplementary materials including additional tables and figures are openly available online (https://osf.io/aew3g/?view_only=7f7d3220febf4094a00d649736842c3a). Descriptive statistics for all relevant variables can be found in the online supplementary materials (OSM).

\section{Are there Differences in Personality Traits Between Athletes of Different Team Sports?}

We conducted variance analyses to examine whether athletes from different sports differed in their personality traits (Table 3). Type of sport was significantly associated with the personality traits openness, $F(15,2302)=3.60, p<.001, \eta^{2}=.02,90 \%$ CI $[.01, .03]$, conscientiousness, $F(15,2300)=3.25, p<.001, \eta^{2}=.02,90 \%$ CI [.01, .02], and extraversion, $F(15,2303)=2.55, p<.001, \eta^{2}=.02,90 \%$ CI $[.00, .02]$. Post-hoc Tukey comparisons revealed that Ice hockey players $(M=3.78)$, Quidditch players $(M=3.88)$, and Soccer players $(M=$ 3.74) were significantly more open than Floorball players $(M=3.49)$. Moreover, both Floorball players $(M=3.47)$ and American Football players $(M=3.51)$ were significantly more conscientious than Rugby players $(M=3.12)$, Ice hockey players $(M=3.26)$, Quidditch players $(M=3.13)$, and Soccer players $(M=3.21)$. Finally, Rugby players $(M=3.56)$, American Football players $(M=3.60)$, and Lacrosse players $(M=3.62)$ were significantly more extraverted than Ice hockey players $(M=3.26)$.

However, the type of sport only explained between 1 and $2 \%$ of the variance in these models. Thus, even though we found some significant differences in personality traits between athletes from different team sports, these differences were very small. A further graphical examination also confirmed that the average personality profiles of players from different team sports mostly resembled each other (see Figure 1). 
Are there Differences in Personality Traits Between Athletes Playing Offense and Defense Positions?

\section{Measurement of Offense and Defense Positions}

First, we examined how the playing positions can be assigned to being offense or defense. We used two different measures of offense/defense for the athletes' playing position: (1) a dichotomous categorization into either offense or defense, (2) and a continuous measure ranging from 0 to $100 \%$ for the positions' involvement in the offense as well as defense phases of the game.

The dichotomous categorization into offense and defense playing positions revealed that whereas some playing positions were almost unanimously categorized as offense (e.g., Wingers in Ice hockey, $N_{\text {off }}=95, N_{\text {def }}=5$ ) or defense (e.g., Goalkeepers in Soccer, $N_{\text {off }}=3, N_{\text {def }}=97$ ) by all athletes, others were more controversial (e.g., Chasers in Quidditch, $N_{\text {off }}=51, N_{\text {def }}=49$ ). Figure 2 presents an exemplary overview of these categorizations of the different playing positions into offense and defense in Ice hockey (for a complete overview OSM). Overall, 35 playing positions were categorized as offense (i.e., at least $80 \%$ of answers indicated offense), 31 as defense (i.e., at least $80 \%$ of answers indicated defense), whereas the remaining 14 playing positions were not categorized clearly.

The continuous measure of the playing positions' involvement in the offense and defense phases of their sport offered a more nuanced picture of playing positions, particularly those being controversial in the dichotomous categorization. Perceived degrees of offense and defense involvements were negatively correlated across all sports and positions, $r=-.56, p<$ .001 , and the correlation became stronger when the data were aggregated within positions, $r=$ $-.84, p<.001$. 


\section{Personality Differences of Offense and Defense Positions}

We examined whether athletes playing offense and defense positions differed in their personality traits. As explained above, we had two different measures of offensiveness/defensiveness: a dichotomous categorization and a continuous and independent measure of the positions' involvement in offense and defense phases of the game.

First, we used the dichotomous categorizations. Participants were categorized into offense and defense players according to their individual answer even when other participants playing the same position answered differently. We performed separate variance analyses for each personality trait and included the categorization, type of sport, and interactions between categorization and type of sport as factors. Table 4 shows the results from these variance analyses. The offense-defense categorization was significantly associated with extraversion, $F(1,2149)=7.21, p=.007, \eta_{\mathrm{p}}^{2}=.003,90 \% \mathrm{CI}[.00, .01]$, such that players categorized as offense $(M=3.48)$ were significantly more extraverted than players categorized as defense $(M$ =3.36). Neither the offense-defense categorization nor the interaction between categorization and sport was significantly associated with any other personality traits (see Table 4 and Figure $3)$.

Next, we examined relations between personality traits and offense and defense positions using the continuous measure of offense and defense involvement (see Figure 4): We performed five separate multilevel regression analyses (athletes nested in sports) with personality traits as the dependent variables and offense involvement and defense involvement as simultaneous predictor variables. Results of these random-intercept multilevel regression models can be found in Table 5. Generally, neither perceived degree of offense involvement nor perceived degree of defense involvement significantly predicted any of the personality traits (all $p>.062$, see Table 5). Thus, regardless of how we operationalized offensiveness and defensiveness of the playing positions, we did not find any meaningful differences in personality traits between offense and defense positions in team sports. 


\section{Are there Differences in Personality Traits Between Athletes Playing Different Playing Positions Within Sports?}

We conducted separate variance analyses for each sport that provided a reasonable sample (i.e., at least two positions with at least 30 participants) to examine personality differences between playing positions. In these variance analyses, personality traits were the dependent variables and main playing position was the independent variable. Playing positions were not significantly associated with any of the personality traits in Ice Hockey, Soccer, Quidditch, or Ultimate Frisbee (for detailed results, see OSM). In Floorball, playing positions were significantly associated with trait extraversion levels, $F(3,247)=4.08, p=.007, \eta_{\mathrm{p}}{ }^{2}=.05$, 90\% CI [.01, .09]. Post-hoc comparisons demonstrated that centers $(M=3.68)$ were significantly more extraverted than defenders $(M=3.19)$. Overall, different playing positions explained between 0 and $5 \%$ of the variance in personality traits in these models.

\section{Discussion}

The current study aimed to comprehensively investigate differences in Big Five personality traits for athletes of (1) different team sports, (2) being offense players and defense players, and (3) playing on different positions within a team sport. Due to the inconsistency of current research evidence, we used an exploratory approach combining statistical and descriptive analyses.

First, we examined differences in Big Five personality traits between athletes of different team sports. We found significant but small main effects regarding the type of sport for openness, conscientiousness, and extraversion explaining 1 to $2 \%$ of variance in these models. Post-hoc tests as well as a graphical examination of differences between sports revealed that there were small differences between several different combinations of sports (e.g., lower levels of Extraversion in Ice hockey vs. Rugby).

Second, we examined differences in Big Five personality traits between athletes playing on offense and defense positions. For this purpose, we assessed offense and defense positions 
in two ways: (1) a dichotomous categorization, (2) and a continuous measure ranging from 0 to $100 \%$ for the offense as well as for the defense. The dichotomous distinction showed that positions were merely not completely described as either defense or offense, and some positions could not be categorized at all (see Figure 2). Further, the continuous measure showed that the athletes' perceived degrees of involvement in offense and defense were correlated but not redundant $(r=-.56, p<.001)$. Positions such as Centers in Floorball, Backcourt players in Handball, and Centre Midfielders in Soccer were almost identically involved in offense and defense phases of the game and may thus not be well represented in a dichotomous categorization (see Figure 2). Overall, we can thus conclude that playing positions may not be easily categorized into offense and defense in all cases. This could explain the unsystematic findings of differences between offense and defense players in team sports (Beckmann \& Trux, 1991; Cameron et al., 2012; Kirkcaldy, 1982b). Therefore, we propose that independent and continuous measures of involvement in offense and defense may paint a more detailed picture of the role of different playing positions in offense and defense. We only found one significant effect between offense and defense position using the categorical approach, in such that offense players were more extraverted than defense players.

Third, we examined differences in Big Five personality traits between athletes playing different playing positions within sports. We found no significant effects for playing positions on personality traits in Ice Hockey, Soccer, Quidditch, or Ultimate Frisbee (for detailed results, see OSM). However, we found a significant effect in Floorball such that centers were more extraverted than defenders. Regarding our third research question more research extending the number of sports in the analyses might be needed, as we were only capable of including five types of sports with 16 positions in the statistical analyses. Yet, the graphical investigation of further position-specific personality profiles also yielded no differences for positions within and between sports. 
In summary, we found only little evidence for differences in Big Five personality traits for athletes of different team sports, offense or defense positions, or different playing positions. We discuss this lack of differences regarding four different aspects: (1) personality assessment, (2) lack of socialization effects in the sample, (3) stereotyping, and (4) operationalization of type of sport and position.

\section{Personality Assessment}

The Big Five traits have been criticized for not being context-related enough because they reflect a rather general approach to assess personality (McAdams, 1995). A reason for the lack of findings regarding differences in Big Five traits might be that those differences might not be reflected in those broad traits. In recent years, the focus has rather lied on more contextand also more sport-specific aspects of personality (Allen et al., 2013). There have been successful approaches assessing personality and individual characteristics in sports other than the Big five like action and state orientation (Beckmann \& Trux, 1991), alexithymia and narcissism (Roberts \& Woodman, 2016), or mental toughness (Liew et al., 2019). Thus, a more context-specific investigation of the personality traits and characteristics for a given sport or aim (e.g., player-selection) might be a more helpful tool to inform the choice for players.

However, these specific traits might then in contrast complicate a comparison between sports types or even teams. Therefore, a compromise between the broad Big Five approach and the specific characteristics approaches could be an investigation of the Big Five traits on the facet level. Indeed, Laborde et al. (2019) found that most traits often assessed in sport psychological research (e.g., trait anxiety or self-efficacy) can be mapped on facets of the Big Five. Further, a lexical approach by Vries (2020) identified sport-related personality traits as being highly correlated with factors of the Big Six (HEXACO; Ashton \& Lee, 2007). Therefore,

the facet level of Big Five or Bix Six personality traits may provide a balanced and fruitful avenue for further research on personality differences within and across team sport. Lack of

\section{Socialization Effects in the Sample}


Second, a potential explanation for the lack of findings in our study may be the composition of the sample. More specifically, it is possible that the effects underlying personality differences in sports did not have a decisive impact in our sample because it was predominantly amateur athletes. However, the mechanisms that may cause associations between sport or physical activity and personality may only become evident for athletes performing on a higher level or having spent a significant amount of time performing their sport. An indication of this is that several studies found differences for athletes of different achievement levels (Kirkcaldy, 1982b; Schurr et al., 1984; Sheard \& Golby, 2010).

Generally, two different mechanisms may be relevant for associations between sport and personality: socialization effects-people change because of their (sport-) environmentor selection effects-people choose and stay in a sport that fits their needs and characteristics. For example, Kruse (1977) found that younger goalkeepers showed higher levels of extraversion and risk-taking behavior than older goalkeepers, pinpointing to a socializing effect on personality for sports. In contrast, the strong linkage between personality traits and performance rather points to a selection effect (see Allen \& Laborde, 2014). However, in order to test the assumption of socialization against the idea of selection, more longitudinal studies on personality development (e.g., Allen et al., 2017) are needed.

Both explanations imply that such differences in personality traits are stronger for athletes performing on a higher level or who have spent a significant amount of time performing their sport. This might not be true for amateur athletes only spending a few hours per month doing sports. In the present study, we conducted a comprehensive investigation of differences in Big Five traits for athletes of different sports and position types. Thus, most athletes included in the sample performed on an amateur level (for more information on performance level and years of practice see OSM). In our sample, only a small percentage of participants reported currently playing on a rather professional level (only $10 \%$ self-reported a performance level of 8 or higher on a scale from 0 to 10 ) or spending a significant amount of time performing their 
sport (only $16 \%$ reported more than 10 hours per week). Thus, effects might be more pronounced in samples with professional athletes and more longitudinal studies on professional athletes performing different types of sports are needed to investigate the bidirectional relation between sport participation and personality development (Allen et al., 2013).

\section{Stereotyping}

A third explanation for the results of our study or, more specifically, the lack thereof may be that ascribed differences between players on different positions could indeed just have anecdotical "evidence". Maybe there is just nothing like an introverted goalie and thus ascribed differences would only be reflected in stereotypical profiles for players on different positions. Indeed, there is evidence that differences in Big Five traits of different playing positions are based on stereotypes (Cameron et al., 2012). In their study, Cameron et al. (2012) assessed selfreported as well as perceived characteristics of hockey players, the latter representing the stereotypical perception of players on different playing positions. They found differences between goalkeepers, defense, and offense players for the stereotypical personality profiles but not for self-reported personality traits. Future research should therefore also focus on the investigation of stereotypical personality traits for athletes of different sport types and positions.

\section{Operationalization of Type of Sport and Position}

Finally, we argue that the way sport type and position type are typically operationalized might be problematic when investigating differences in personality traits. Regarding sport type, differences have been mostly found between different groups of sports (e.g., individual versus team sports; Nia \& Besharat, 2010) and only rarely between single sports (Trninić et al., 2016). For example, it is typically found that team sport athletes are more extraverted than individual sport athletes (Allen et al., 2013). However, in our study, we also found significant, though smaller, differences in extraversion within this category of team sports, for example between different team sports or even players within a sport. Therefore, categories such as type of sport may not be the best approach to characterizing the relevant aspects of sport. More specific and 
continuous characteristics of sports may be more suitable to detect and explain subtle differences between sports and the underlying mechanisms influencing them. For example, the relevant factor influencing the level of extraversion might be the level of sociality for a given sport (e.g., Ice hockey versus Rugby) and position (Bruner et al., 2011) rather than the type of sport or position itself. A more precise investigation of the characteristics of sports might therefore be useful (Terwiel et al., 2020).

Regarding position type, we conclude that playing position in team sports may not be easily categorized into offense and defense as often done. Instead, we again propose that more specific and continuous measures of involvement in offense and defense may paint a more detailed picture of the role of different playing positions in the offense and defense phases of the game. This would eventually help to investigate the influence of the playing positions on personality or vice versa more precisely.

\section{Limitations}

Besides the well-known limitations of self-report studies and WEIRD samples (Gosling, Sandy, John, \& Potter, 2010), this current study was subject to two more specific limitations. First, we only investigated 16 different team sports. However, the number of sports is much larger and steadily growing (Lipoński et al., 2003). Nonetheless, the results of the current study represent a first comprehensive attempt to investigate differences in Big Five personality traits for athletes of different sport types and position types. Further, we included rather untypical and newly formed sports like Quidditch and Jugger into our data collection to give a broad overview and allow us to generalize the presented results.

Second, the data collection of the study took part during the global Covid-19 pandemic. It has been shown that the pandemic influences athletes on several levels like motivation, achievement, performance, or psychosocial dimensions (Samuel et al., 2020).

Nevertheless, there is first evidence that exercise frequency was not negatively influenced, especially not for athletes who regularly trained pre-pandemic (Brand et al., 2020). 
Additionally, personality has been found to be relatively stable concerning to life events (Denissen et al., 2019). Thus, we can assume that the constructs examined in this study, and in turn, its results, were not significantly affected by the Covid-19 pandemic.

\section{Conclusion}

We examined differences in Big Five personality traits between athletes of different team sports, offense and defense players, and different playing positions. We found only little evidence for differences in Big Five personality traits based on team sport type and position type. We discuss four possible explanations for our findings, namely the broad focus of the Big Five traits, the lack of socialization effects in amateur athletes, stereotyping of position-specific personality profiles, and the way sport type and positions are assessed. Further investigation of the bidirectional relation between sport performance and personality development, personality traits of professional athletes, and stereotypical perception of athletes playing on different positions is needed.

\section{Acknowledgements}

We would like to thank Flavio Schröder, Carolin Segieth, Anna Mechnig, and Verena Swarlik for their support during data collection and data preparation. Further, we would like to thank Peter Hähner and Verena Maag for useful comments on an earlier version of this manuscript. 


\section{Tables}

Table 1. Means, standard deviations, internal consistency, and sample items for the selfreported Big Five personality traits

\begin{tabular}{lcccl}
\hline \multicolumn{1}{c}{ Trait } & $M$ & $S D$ & $\begin{array}{c}\text { Internal } \\
\text { consistency }(\alpha)\end{array}$ & \multicolumn{1}{c}{$\begin{array}{c}\text { Sample item } \\
\text { (I am someone who...) }\end{array}$} \\
\hline Openness & 3.68 & 0.70 & .66 & Is fascinated by art, music, or literature \\
Conscientiousness & 3.42 & 0.58 & .74 & Is persistent, works until the task is finished. \\
Extraversion & 3.38 & 0.77 & .74 & Is full of energy. \\
Agreeableness & 3.66 & 0.69 & .72 & Is respectful, treats others with respect. \\
Negative Emotionality & 2.61 & 0.87 & .80 & Worries a lot. \\
& & & &
\end{tabular}


Table 2. Number of participants, age, and gender distributions for each sport in the final sample

\begin{tabular}{|c|c|c|c|c|c|c|c|c|}
\hline \multirow[b]{2}{*}{ Sport } & \multicolumn{3}{|c|}{ Number of raters } & \multicolumn{2}{|c|}{ Age } & \multicolumn{3}{|c|}{ Gender } \\
\hline & Offense & Defense & Total & M & $\mathrm{SD}$ & Male & Female & Diverse \\
\hline American Football & 51 & 44 & 99 & 28.80 & 28.80 & 66 & 33 & 0 \\
\hline Baseball & 7 & 40 & 49 & 29.20 & 29.20 & 47 & 2 & 0 \\
\hline Basketball & 32 & 20 & 56 & 27.48 & 27.48 & 46 & 10 & 0 \\
\hline Field Hockey & 47 & 98 & 147 & 28.08 & 28.08 & 116 & 31 & 0 \\
\hline Floorball & 108 & 142 & 258 & 27.01 & 27.01 & 164 & 94 & 0 \\
\hline Football/Soccer & 93 & 212 & 322 & 25.60 & 25.60 & 301 & 21 & 0 \\
\hline Handball & 60 & 48 & 111 & 24.32 & 24.32 & 88 & 23 & 0 \\
\hline Ice hockey & 140 & 309 & 472 & 29.56 & 29.56 & 410 & 58 & 4 \\
\hline Jugger & 33 & 24 & 57 & 27.70 & 27.70 & 44 & 12 & 1 \\
\hline Lacrosse & 34 & 26 & 62 & 26.85 & 26.85 & 44 & 18 & 0 \\
\hline Quidditch & 34 & 58 & 0 & 23.90 & 23.90 & 41 & 39 & 13 \\
\hline Rugby Union & 70 & 53 & 132 & 26.62 & 26.62 & 124 & 8 & 0 \\
\hline Softball & 6 & 30 & 40 & 30.82 & 30.82 & 14 & 26 & 0 \\
\hline Ultimate Frisbee & 102 & 76 & 187 & 27.25 & 27.25 & 135 & 50 & 2 \\
\hline Volleyball & 115 & 43 & 162 & 25.48 & 25.48 & 91 & 71 & 0 \\
\hline Water Polo & 33 & 40 & 75 & 24.16 & 24.16 & 60 & 15 & 0 \\
\hline
\end{tabular}


Table 3. Associations between type of team sport and personality trait levels

\begin{tabular}{|c|c|c|c|c|c|c|}
\hline DV & IV & $\mathrm{df}$ & $\mathrm{F}$ & $\eta_{p}^{2}$ & $\mathrm{p}$-value & significant post-hoc comparisons \\
\hline Openness & sport & 15,2302 & 3.60 & .023 & $<.001$ & $\begin{array}{l}\text { Football/Soccer }>\text { Floorball } \\
\text { Ice Hockey }>\text { Floorball } \\
\text { Quidditch }>\text { Floorball }\end{array}$ \\
\hline Conscientiousness & sport & 15,2300 & 3.25 & .021 & $<.001$ & $\begin{array}{l}\text { Football/Soccer }>\text { American Football } \\
\text { Quidditch }>\text { American Football } \\
\text { Rugby Union }>\text { American Football } \\
\text { Football/Soccer }>\text { Floorball } \\
\text { Ice Hockey }>\text { Floorball } \\
\text { Quidditch }>\text { Floorball } \\
\text { Rugby Union > Floorball }\end{array}$ \\
\hline Extraversion & sport & 15,2303 & 2.55 & .016 & $<.001$ & $\begin{array}{l}\text { Ice Hockey > American Football } \\
\text { Lacrosse > Ice Hockey } \\
\text { Rugby Union > Ice Hockey }\end{array}$ \\
\hline Agreeableness & sport & 15,2302 & 1.54 & .010 & .083 & - \\
\hline Emotional Stability & sport & 15,2302 & 1.11 & .007 & .342 & - \\
\hline
\end{tabular}


Table 4. Associations of type of team sport, offense-defense categorization, and their interaction with personality trait levels

\begin{tabular}{|c|c|c|c|c|}
\hline Effect & df & $\mathrm{F}$ & $\eta_{\mathrm{p}}^{2}$ & p-value \\
\hline \multicolumn{5}{|l|}{ DV: Openness } \\
\hline sport & 14,2148 & 3.40 & .022 & $<.001$ \\
\hline OD-categorization & 1,2148 & 0.12 & $<.001$ & .726 \\
\hline sport x OD-categorization & 14,2148 & 1.75 & .011 & .041 \\
\hline \multicolumn{5}{|c|}{ DV: Conscientiousness } \\
\hline sport & 14,2147 & 2.91 & .019 & $<.001$ \\
\hline OD-categorization & 1,2147 & 0.00 & $<.001$ & .953 \\
\hline sport x OD-categorization & 14,2147 & 0.59 & .004 & .878 \\
\hline \multicolumn{5}{|l|}{ DV: Extraversion } \\
\hline sport & 14,2149 & 2.10 & .013 & .010 \\
\hline OD-categorization & 1,2149 & 7.21 & .003 & .007 \\
\hline sport x OD-categorization & 14,2149 & 1.05 & .007 & .395 \\
\hline \multicolumn{5}{|l|}{ DV: Agreeableness } \\
\hline sport & 14,2148 & 1.56 & .010 & .084 \\
\hline OD-categorization & 1,2148 & 0.04 & $<.001$ & .835 \\
\hline sport x OD-categorization & 14,2148 & 0.88 & .006 & .578 \\
\hline \multicolumn{5}{|c|}{ DV: Negative Emotionality } \\
\hline sport & 14,2148 & 1.05 & .007 & .397 \\
\hline OD-categorization & 1,2148 & 0.30 & $<.001$ & .582 \\
\hline sport x OD-categorization & 14,2148 & 0.86 & .006 & .602 \\
\hline
\end{tabular}

Note. OD-categorization represents the offense-defense categorization. Participants were categorized according to their individual answer even when other participants playing the same position answered differently. 
Table 5. Multilevel models regressing personality traits on perceived degree of offense and defense involvement of the players' main positions

\begin{tabular}{|c|c|c|c|c|c|}
\hline Effect & Estimate & $95 \% \mathrm{CI}$ & $\mathrm{df}$ & $\mathrm{t}$ & $\mathrm{p}$-value \\
\hline \multicolumn{6}{|l|}{ Openness } \\
\hline Intercept & 3.659 & {$[3.595,3.724]$} & 15 & 119.92 & $<.001$ \\
\hline Offense involvement & 0.001 & {$[-0.001,0.002]$} & 1876 & 0.99 & .323 \\
\hline Defense involvement & 0.000 & {$[-0.002,0.001]$} & 1883 & -0.16 & .872 \\
\hline \multicolumn{6}{|l|}{ Conscientiousness } \\
\hline Intercept & 3.300 & {$[3.219,3.382]$} & 11 & 88.93 & $<.001$ \\
\hline Offense involvement & 0.000 & {$[-0.001,0.002]$} & 1886 & 0.20 & .844 \\
\hline Defense involvement & -0.001 & {$[-0.003,0.001]$} & 1888 & -1.16 & .248 \\
\hline \multicolumn{6}{|l|}{ Extraversion } \\
\hline Intercept & 3.392 & {$[3.336,3.448]$} & 9 & 136.69 & $<.001$ \\
\hline Offense involvement & 0.002 & {$[<0.000,0.003]$} & 1631 & 1.87 & .062 \\
\hline Defense involvement & -0.001 & {$[-0.003,>0.000]$} & 1772 & -1.50 & .133 \\
\hline \multicolumn{6}{|l|}{ Agreeableness } \\
\hline Intercept & 3.657 & {$[3.610,3.705]$} & 9 & 172.59 & $<.001$ \\
\hline Offense involvement & -0.001 & {$[-0.002,0.001]$} & 1578 & -0.85 & .397 \\
\hline Defense involvement & -0.001 & {$[-0.002,>0.000]$} & 1756 & -1.29 & .199 \\
\hline \multicolumn{6}{|l|}{ Negative Emotionality } \\
\hline Intercept & 2.609 & {$[2.553,2.665]$} & 6 & 110.45 & $<.001$ \\
\hline Offense involvement & 0.001 & {$[-0.001,0.002]$} & 1189 & 0.62 & .534 \\
\hline Defense involvement & 0.001 & {$[-0.001,0.003]$} & 1600 & 1.19 & .235 \\
\hline
\end{tabular}

Note. Multilevel models had participants nested in sports. Perceived degree of offense and defense involvement were grand-mean centered. Results are from random-intercept models. 


\section{Figures}

\begin{tabular}{|c|c|c|c|c|}
\hline 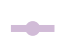 & American Footbal1- & Floorball & Jugger & $=-$ Softball \\
\hline$\rightarrow$ & Baseball & Football/Soccer- & Lacrosse & Ultimate Frisbee \\
\hline & Basketball & Handball & Quidditch & $\sim$ Volleyball \\
\hline & Field Hockey & Ice Hockey & Rugby Uni & - Water Polo \\
\hline
\end{tabular}

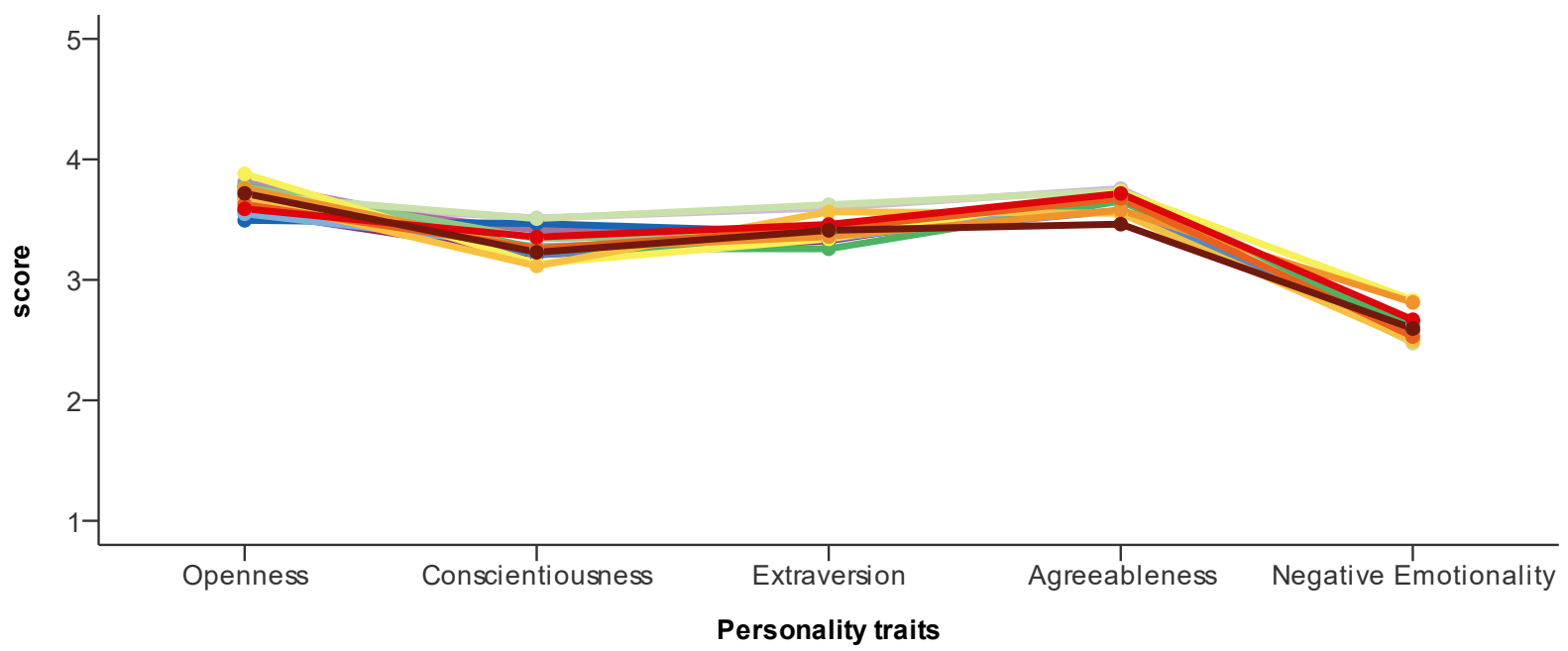

Figure 1. Typical Big Five personality profiles of athletes from different team sports. 
Ice Hockey
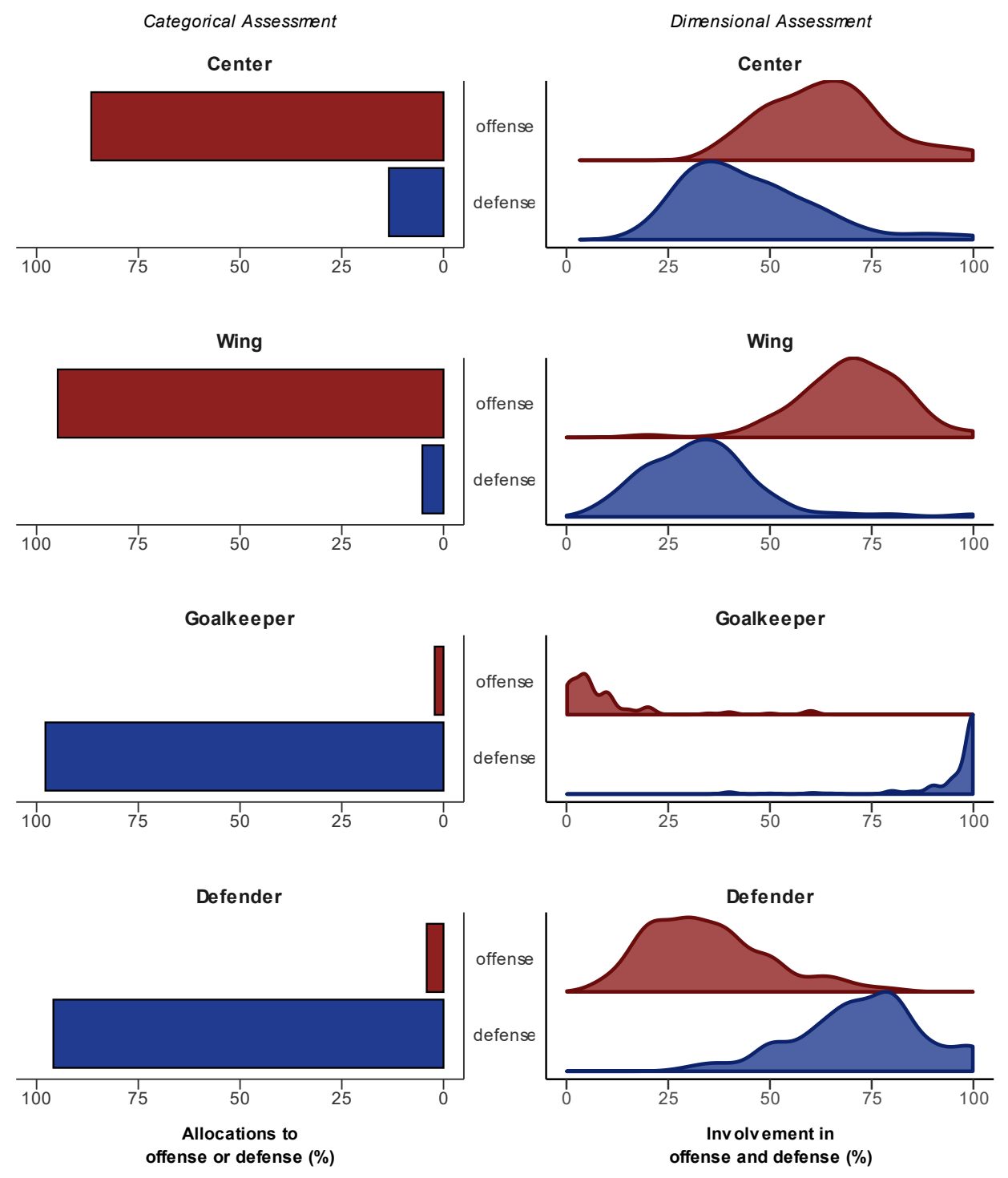

Figure 2. Comparison of categorical measurement (left) and dimensional measurement(right) of offense/defense of the different playing positions in Ice hockey. The left panel displays for each positions the percentage of players that categorized this position as offense or defense, respectively. The right panel displays for the same positions how much the positions are typically involved in offense and defense phases of the game, respectively, as the distribution of answers across all athletes playing this position. Figures for the remaining sports can be found in the OSM. 


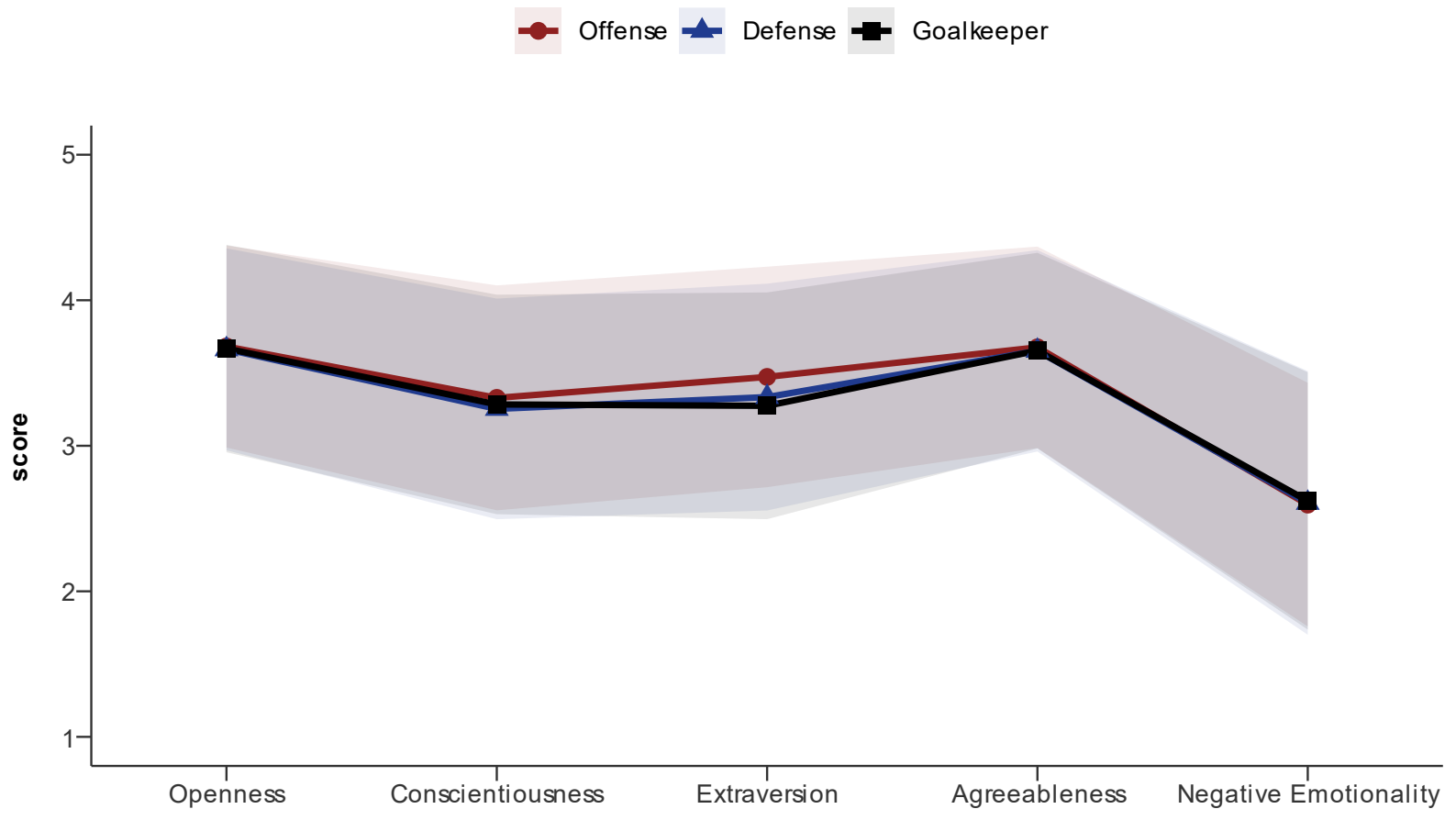

Figure 3. Typical Big Five personality profiles of goalkeepers, defense players, and offense players. Lines represent mean values, shaded areas represent values one standard deviation above and below the mean. 
A

\section{Involvement in Offense Phases}

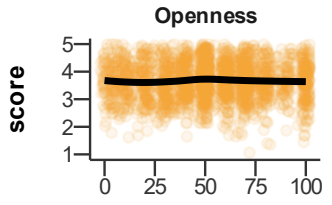

B

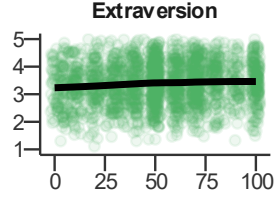

Involvement (\%)
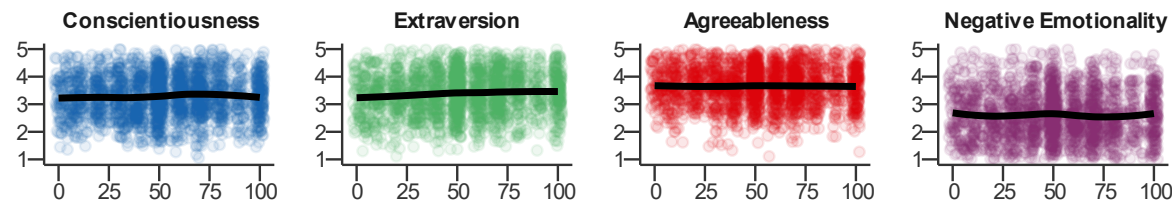

\section{Involvement in Defense Phases}

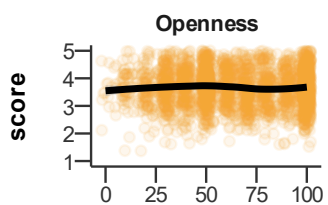

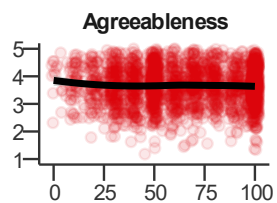

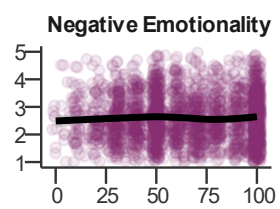

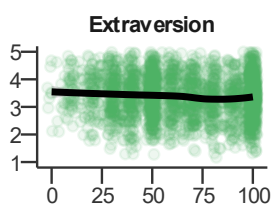

Involvement (\%)

Figure 4. Associations between Big Five personality traits and involvement in offense and defense phases of the game. Dots represent the individual data points, the lines are lowess regression lines. 


\section{References}

Aidman, E., \& Schofield, G. (2004). Personality and individual differences in sport. In Sport psychology: Theory, applications and issues (2nd ed., pp. 22-47). John Wiley \& Sons Australia.

Allen, M. S., Greenlees, I., \& Jones, M. (2011). An investigation of the five-factor model of personality and coping behaviour in sport. Journal of Sports Sciences, 29(8), 841-850. https://doi.org/10.1080/02640414.2011.565064

Allen, M. S., Greenlees, I., \& Jones, M. (2013). Personality in sport: a comprehensive review. International Review of Sport and Exercise Psychology, 6(1), 184-208. https://doi.org/10.1080/1750984X.2013.769614

Allen, M. S., \& Laborde, S. (2014). The role of personality in sport and physical activity. Current Directions in Psychological Science, 23(6), 460-465. https://doi.org/10.1177/0963721414550705

Allen, M. S., Magee, C. A., Vella, S. A., \& Laborde, S. (2017). Bidirectional associations between personality and physical activity in adulthood. Health Psychology, 36(4), 332-336. https://doi.org/10.1037/hea0000371

Ashton, M. C., \& Lee, K. (2007). Empirical, theoretical, and practical advantages of the HEXACO model of personality structure. Personality and Social Psychology Review : An Official Journal of the Society for Personality and Social Psychology, Inc, 11(2), 150-166. https://doi.org/10.1177/1088868306294907

Bakker, F. C. (1991). Development of personality in dancers: A longitudinal study. Personality and Individual Differences, 12(7), 671-681. https://doi.org/10.1016/0191-8869(91)90222W

Beckmann, J., \& Trux, J. (1991). Wen lasse ich wo spielen? Sportpsychologie, 5(3), 18-21. 
Bojanić, Ž., Nedeljković, J., Šakan, D., Mitić, P. M., Milovanović, I., \& Drid, P. (2019). Personality Traits and Self-Esteem in Combat and Team Sports. Frontiers in Psychology, 10, 2280. https://doi.org/10.3389/fpsyg.2019.02280

Brand, R., Timme, S., \& Nosrat, S. (2020). When Pandemic Hits: Exercise Frequency and Subjective Well-Being During COVID-19 Pandemic. Frontiers in Psychology, 11, 570567. https://doi.org/10.3389/fpsyg.2020.570567

Bruner, M. W., Hall, J., \& Côté, J. (2011). Influence of sport type and interdependence on the developmental experiences of youth male athletes. European Journal of Sport Science, 11(2), 131-142. https://doi.org/10.1080/17461391.2010.499969

Cameron, J. E., Cameron, J. M., Dithurbide, L., \& Lalonde, R. N. (2012). Personality traits and stereotypes associated with ice hockey positions. Journal of Sport Behavior, 35(2), 109-124.

Castanier, C., Le Scanff, C., \& Woodman, T. (2010). Who takes risks in high-risk sports? A typological personality approach. Research Quarterly for Exercise and Sport, 81(4), 478484.

Čavala, M., Trninić, V., Jašić, D., \& Tomljanović, M. (2013). The influence of somatotype components and personality traits on the playing position and the quality of top Croatian female cadet handball players. Collegium Antropologicum, 37(2), 97-100.

Cooper, R., \& Payne, R. (1972). Personality orientations and performance in soccer teams. British Journal of Social and Clinical Psychology, 11(1), 2-9.

Costa, P. T., \& McCrae, R. R. (1992). Four ways five factors are basic. Personality and Individual Differences, 13(6), 653-665. https://doi.org/10.1016/0191-8869(92)90236-I

Cox, R. H., \& Yoo, H. S. (1995). Playing position and psychological skill in American football. Journal of Sport Behavior, 18(3), 183.

Crysel, L. C., Cook, C. L., Schember, T. O., \& Webster, G. D. (2015). Harry Potter and the measures of personality: Extraverted Gryffindors, agreeable Hufflepuffs, clever 
Ravenclaws, and manipulative Slytherins. Personality and Individual Differences, 83, 174 179. https://doi.org/10.1016/j.paid.2015.04.016

Denissen, J. J. A., Bleidorn, W., Hennecke, M., Luhmann, M., Orth, U., Specht, J., \& Zimmermann, J. (2018). Uncovering the Power of Personality to Shape Income. Psychological Science, 29(1), 3-13. https://doi.org/10.1177/0956797617724435

Denissen, J. J. A., Luhmann, M., Chung, J. M., \& Bleidorn, W. (2019). Transactions between life events and personality traits across the adult lifespan. Journal of Personality and Social Psychology, 116(4), 612-633. https://doi.org/10.1037/pspp0000196

Diener, E [E.], \& Lucas, R. E. (2020). Personality traits. In R. Biswas-Diener \& E. Diener (Eds.), Noba textbook series: Psychology. DEF Publishers. http://noba.to/96u8ecgw

Downward, P., \& Rasciute, S. (2011). Does sport make you happy? An analysis of the wellbeing derived from sports participation. International Review of Applied Economics, 25(3), 331-348. https://doi.org/10.1080/02692171.2010.511168

Eagleton, J. R., McKelvie, S. J., \& Man, A. de (2007). Extraversion and neuroticism in team sport participants, individual sport participants, and nonparticipants. Perceptual and Motor Skills, 105(1), 265-275. https://doi.org/10.2466/pms.105.1.265-275

Egloff, B., \& Jan Gruhn, A. (1996). Personality and endurance sports. Personality and Individual Differences, 21(2), 223-229. https://doi.org/10.1016/0191-8869(96)00048-7

Evans, M. B., Eys, M. A., \& Bruner, M. W. (2012). Seeing the "we" in "me" sports: The need to consider individual sport team environments. Canadian Psychology, 53(4), 301-308. https://doi.org/10.1037/a0030202

Fasold, F., Inzenhofer, V., Lingner, K., Noël, B., \& Klatt, S. (2020). Personality traits of handball goalkeepers. Journal of Human Sport and Exercise, 15(2). https://doi.org/10.14198/jhse.2020.152.04 
Fields, J. B., Merrigan, J. J., White, J. B., \& Jones, M. T. (2018). Body Composition Variables by Sport and Sport-Position in Elite Collegiate Athletes. Journal of Strength and Conditioning Research, $\quad 32(11), \quad 3153-3159$. https://doi.org/10.1519/JSC.0000000000002865

Garland, D. J., \& Barry, J. R. (1988). The Effects of Personality and Perceived Leader Behaviors on Performance in Collegiate Football. The Psychological Record, 38(2), 237247. https://doi.org/10.1007/BF03395019

Gosling, S. D., Sandy, C. J., John, O. P., \& Potter, J. (2010). Wired but not WEIRD: The promise of the Internet in reaching more diverse samples. The Behavioral and Brain Sciences, 33(2-3), 94-95. https://doi.org/10.1017/S0140525X10000300

Gosling, S. D., Sandy, C. J., \& Potter, J. (2010). Personalities of Self-Identified "Dog People" and "Cat People". Anthrozoös, 23(3), 213-222. https://doi.org/10.2752/175303710X12750451258850

Jakob, L., Garcia-Garzon, E., Jarke, H., \& Dablander, F. (2019). The Science Behind the Magic? The Relation of the Harry Potter "Sorting Hat Quiz" to Personality and Human Values. Collabra: Psychology, 5(1), Article 31. https://doi.org/10.1525/collabra.240

Johnson, R. W., \& Morgan, W. P [W. P.] (1981). Personality characteristics of college athletes in different sports. Scandinavian Journal of Sports Science, 3(2), 41-49.

Karcher, C., \& Buchheit, M. (2014). On-court demands of elite handball, with special reference to playing positions. Sports Medicine (Auckland, N.Z.), 44(6), 797-814. https://doi.org/10.1007/s40279-014-0164-z

Kirkcaldy, B. D. (1982a). Personality and sex differences related to positions in team sports. International Journal of Sport Psychology.

Kirkcaldy, B. D. (1982b). Personality profiles at various levels of athletic participation. Personality and Individual Differences, 3(3), 321-326. 
Kőnig-Görögh, D., Gyömbér, N., Szerdahelyi, Z., Laoues, N., Olvasztóné Balogh, Z., TóthHosnyánszki, A., \& Ökrös, C. (2017). Personality profiles of junior handball players: Differences as a function of age, gender, and playing positions. Cognition, Brain, Behavior. An Interdisciplinary Journal, 21(4), 237-247. https://doi.org/10.24193/cbb.2017.21.15

Kruse, V. (1977). Zu Persönlichkeitseigenschaften von Fußball-und Tischtennisspielern. Leistungssport, 7, 231-236.

Laborde, S., Allen, M. S., Katschak, K., Mattonet, K., \& Lachner, N. (2019). Trait personality in sport and exercise psychology: A mapping review and research agenda. International Journal of Sport and Exercise Psychology, 36(4), 1-16. https://doi.org/10.1080/1612197X.2019.1570536

Liew, G. C., Kuan, G., Chin, N. S., \& Hashim, H. A. (2019). Mental toughness in sport. German Journal of Exercise and Sport Research, 49(4), 381-394. https://doi.org/10.1007/s12662-019-00603-3

Lipoński, W., Farmer, M., \& Hagarty, K. (2003). World sports encyclopedia. Oficyna Wydawnicza Atena.

McAdams, D. P. (1995). What Do We Know When We Know a Person? Journal of Personality, 63(3), 365-396. https://doi.org/10.1111/j.1467-6494.1995.tb00500.x

McCrae, R. R., \& Costa, P. T. (1987). Validation of the five-factor model of personality across instruments and observers. Journal of Personality and Social Psychology, 52(1), 81-90. https://doi.org/10.1037/0022-3514.52.1.81

Morgan, W. P [William P.], \& Pollock, M. L. (1977). Psychologic characterization of the elite distance runner. Annals of the New York Academy of Sciences, 301(1), 382-403.

Nation, J. R., \& LeUnes, A. D. (1983). Personality characteristics of intercollegiate football players as determined by position, classification, and redshirt status. Journal of Sport Behavior. 
Nia, M. E., \& Besharat, M. A. (2010). Comparison of athletes' personality characteristics in individual and team sports. Procedia - Social and Behavioral Sciences, 5, 808-812. https://doi.org/10.1016/j.sbspro.2010.07.189

Ogilvie, B. C., \& Pool, C. C. (1974). Aerobatic Pilots-Why do they fly that way? The Physician and Sportsmedicine, 2(11), 63-65.

O'Sullivan, D. M., Zuckerman, M., \& Kraft, M. (1998). Personality characteristics of male and female participants in team sports. Personality and Individual Differences, 25(1), 119-128. https://doi.org/10.1016/S0191-8869(98)00036-1

Qualtrics. (2020) (Version 02/2020) [Computer software]. Provo, Utah, USA. https://www.qualtrics.com

R Core Team. (2020). R: A language and environment for statistical computing [Computer software]. Vienna, Austria.

Rhea, D. J., \& Martin, S. (2010). Personality Trait Differences of Traditional Sport Athletes, Bullriders, and other Alternative Sport Athletes. International Journal of Sports Science \& Coaching, 5(1), 75-85. https://doi.org/10.1260/1747-9541.5.1.75

Rhodes, R. E., \& Smith, N. E. I. (2006). Personality correlates of physical activity: A review and meta-analysis. British Journal of Sports Medicine, 40(12), 958-965. https://doi.org/10.1136/bjsm.2006.028860

Roberts, R., \& Woodman, T. (2016). Contemporary personality perspectives in sport psychology. In S. D. Mellalieu \& S. Hanton (Eds.), Contemporary advances in sport psychology: A review (pp. 1-27). Routledge.

Rogulj, N., Srhoj, V., Nazor, M., Srhoj, L., \& Čavala, M. (2005). Some anthropologic characteristics of elite female handball players at different playing positions. Collegium Antropologicum, 29(2), 705-709. 
Samuel, R. D., Tenenbaum, G., \& Galily, Y. (2020). The 2020 Coronavirus Pandemic as a Change-Event in Sport Performers' Careers: Conceptual and Applied Practice Considerations. Frontiers in Psychology, $\quad$ 11, 567966. https://doi.org/10.3389/fpsyg.2020.567966

Schmitt, D. P., Allik, J., McCrae, R. R., \& Benet-Martínez, V. (2007). The geographic distribution of Big Five personality traits: Patterns and profiles of human self-description across 56 nations. Journal of Cross-Cultural Psychology, 38(2), 173-212.

Schurr, K. T., Nisbet, J., \& Wallace, D. (1984). Myers-Briggs Type Inventory characteristics of more and less successful players on an American football team. Journal of Sport Behavior, $7(2), 47$.

Sheard, M., \& Golby, J. (2010). Personality hardiness differentiates elite-level sport performers. International Journal of Sport and Exercise Psychology, 8(2), 160-169. https://doi.org/10.1080/1612197X.2010.9671940

Sindik, J. (2011). Differences between top senior basketball players from different team positions in Big Five personality traits. Acta Kinesiologica, 5(2), 31-35.

Soto, C. J., \& John, O. P. (2017). Short and extra-short forms of the Big Five Inventory-2: The BFI-2-S and BFI-2-XS. Journal of Research in Personality, 68, 69-81. https://doi.org/10.1016/j.jrp.2017.02.004

Terwiel, S., Rauthmann, J. F., \& Luhmann, M. (2020). Using the situational characteristics of the DIAMONDS taxonomy to distinguish sports to more precisely investigate their relation with psychologically relevant variables. PLoS ONE, 15(10), e0241013. https://doi.org/10.1371/journal.pone.0241013

Tok, S. (2011). The Big Five personality traits and risky sport participation. Social Behavior and Personality, 39(8), 1105-1111. https://doi.org/10.2224/sbp.2011.39.8.1105 
Trninić, V., Trninić, M., \& Penezić, Z. (2016). Personality differences between the players regarding the type of sport and age. Acta Kinesiologica, 10(2), 69-74.

Vries, R. E. de (2020). The Main Dimensions of Sport Personality Traits: A Lexical Approach. Frontiers in Psychology, 11, 2211. https://doi.org/10.3389/fpsyg.2020.02211

Wilson, K. E., \& Dishman, R. K. (2015). Personality and physical activity: A systematic review and meta-analysis. Personality and Individual Differences, 72, 230-242. https://doi.org/10.1016/j.paid.2014.08.023

Zekioglu, A., Tatar, A., \& Ozdemir, H. (2018). The comparison of personality profiles of sports and non-sports group by six-factor model of personality. Universal Journal of Educational Research, 6(11), 2683-2690. https://doi.org/10.13189/ujer.2018.061135 